\title{
Targeting Neuroinflammation in Neovascular Retinal Diseases
}

\author{
Tianxi Wang, Demetrios I. Tsirukis and Ye Sun* \\ Department of Ophthalmology, Boston Children's Hospital, Harvard Medical School, Boston, MA, United States
}

Retinal blood vessels provide the necessary energy, nutrients and oxygen in order to support visual function and remove harmful particles from blood, thus acting to protect neuronal cells. The homeostasis of the retinal vessels is important for the maintenance of retinal visual function. Neovascularization is the most common cause of blindness in patients with retinopathy. Previous studies have shown that inflammatory mediators are known key regulators in retinopathy, but their causal link has been elusive. Although inflammation is often thought to arise from inflammatory cells like macrophages, neutrophils, and resident microglia, retinal neurons have also been reported to contribute to inflammation, through inflammatory signals, which mediate blood vessel growth. Therefore, it is important to explore the detailed mechanisms of neuroinflammation's effects on retinal neovascularization. This review looks to summarize current research on the relationship between retinal angiogenesis and neuroinflammation in retinopathy,

OPEN ACCESS

Edited by:

Zhuo Shao,

University of Toronto, Canada

Reviewed by:

José Carlos Rivera, University of Montreal, Canada

Kyriaki Thermos,

University of Crete, Greece

*Correspondence:

Ye Sun

ye.sun@childrens.harvard.edu

Specialty section: This article was submitted to

Neuropharmacology,

a section of the journal

Frontiers in Pharmacology

Received: 30 November 2019

Accepted: 20 February 2020

Published: 10 March 2020

Citation:

Wang T, Tsirukis DI and Sun Y (2020) Targeting Neuroinflammation

in Neovascular Retinal Diseases.

Front. Pharmacol. 11:234.

doi: 10.3389/fphar.2020.00234 as well as the potential effects of neuroinflammation on retinal neovascularization in different animal models.

Keywords: neuroinflammation, neovascularization, retina, retinal disease, pharmacology

\section{RETINAL NEOVASCULAR DISEASES AND NEUROINFLAMMATION}

The retina is part of the central nervous system and retinal blood vessels are functionally analogous to the cerebral blood vessels (Campbell and Humphries, 2012). The blood-retinal barrier (BRB) is formed by glial cells, pericytes and endothelial cells (Cunha-Vaz et al., 2011). Retinal blood vessels provide abundant energy and oxygen to neuronal and glial cells, while neuronal and glial cells provide growth factors for retinal blood vessels. In order to facilitate this, there is frequent and effective communication between neurons and vessels in the retina. Additionally, the BRB plays an important role in maintaining the function of the retina. An injury to the BRB causes neuroinflammation, which can result in BRB breakdown and neovascularization (NV). There is abundant evidence indicating that retinal NV is often accompanied by neuroinflammation (Connor et al., 2007; Sun et al., 2015, 2017), but how exactly neuroinflammation regulates retinal NV remains largely unknown.

Neuroinflammation causes neuronal damage, leading to the development and progression of a variety of neurodegenerative diseases such as Alzheimer's disease, Parkinson's disease, and retinal degeneration (Xing et al., 2016), as well as retinal neovascular diseases (Tonade et al., 2016; Sun et al., 2017). This damage triggers a rapid transformation of the retinal microglia into an activated state, switching its function from patrol to shield of the injured site (Chang et al., 2009). Activated microglia continue to secrete inflammatory mediators that act on other cells to induce and amplify 
uncontrolled inflammatory responses. Retinal neurons, such as photoreceptors, have been recently reported to signal for blood vessel growth through inflammatory signals (Tonade et al., 2016; Sun et al., 2017). Pro-inflammatory cytokines and chemokines can cause neuronal apoptosis or death (Leung et al., 2016).

Neovascularization is the proliferation of new micro blood vessels in the retina. In clinic, these are called intraretinal microvascular abnormalities, as well as retinal NV when these new blood vessels grow to the surface of the retina (Campochiaro, 2013). The biggest difference between normal retinal vessels and new blood vessels is that the new blood vessels lack tight junction proteins, which means that the plasma in the NV leaks into the surrounding tissue, such as the vitreous, and causes the degeneration of the vitreous, resulting in vitreous hemorrhage. Furthermore, the subsequent pull on the retina by degraded vitreous may result in retinal detachment, which involves the macula and results in severe vision loss (Campochiaro, 2013). $\mathrm{NV}$ occurs in many ocular diseases, such as retinopathy of prematurity (ROP), age-related macular degeneration (AMD), and diabetic retinopathy (DR). However, the causes of retinal NV may be different among the different types of retinopathy.

Choroidal NV (CNV) is the major cause of vision loss in neovascular AMD. $\mathrm{CNV}$ is a process that involves the participation of vascular and extravascular components, such that $\mathrm{CNV}$ results in a complex tissue, which is composed of blood vessels, glial cells, myofibroblasts, retinal pigment epithelia, and inflammatory cells (Spaide, 2006). Immune dysregulation and inflammatory processes have been linked with CNV pathogenesis both clinically and experimentally (Ambati et al., 2013; Kumar et al., 2014; Chen et al., 2016). The release of a series of pro-angiogenic factors may be one of the causes of inflammatory cells triggering angiogenesis (Noel et al., 2007). Neutrophil or macrophage depletion was shown to reduce CNV formation (Espinosa-Heidmann et al., 2003; Zhou et al., 2005). Similarly, macrophage depletion was associated with decreased vascular endothelial growth factor (VEGF) production in laser-induced CNV (Espinosa-Heidmann et al., 2003). The recruitment of blood-derived macrophages appears to be more associated with CNV than resident microglia by bone marrow transplantation experiments (Caicedo et al., 2005). In addition, photoreceptors can control proliferative angiogenesis by modulating photoreceptor inflammatory signals (Sun et al., 2017).

Retinopathy of prematurity is a major cause of blindness in children (Lutty et al., 2006; Tasman et al., 2006; Blencowe et al., 2012). With advances in neonatal care, smaller and more premature infants who are at high risk for ROP are saved; therefore, increasing the overall incidence of ROP. Currently there is no preventative treatment for ROP. To find new ROP treatments in addition to earlier preventative therapies, understanding the molecular mechanisms of ROP development becomes crucial. Photoreceptors have been reported to play an important role in the ROP pathogenesis (Akula et al., 2007a,b). Oxygen-induced retinopathy (OIR) is a classical and effective model for studying NV in the ROP (Smith et al., 1994; Connor et al., 2009). In this model, relative hypoxia leads to an increase in the expression of VEGF in the retina neurons and glial cells (Sun et al., 2015). At the same time, hypoxia can also cause neuroinflammation by activating microglia (Deliyanti et al., 2017). The continually activated microglia promote inflammation and VEGF expression, and eventually exacerbate NV.

Diabetic retinopathy is a common and complex diabetic complication. Hyperglycemia and dyslipidemia are closely related to the development of DR (Fu et al., 2016, 2018). NV often occurs in the later stages of DR (Klaassen et al., 2013; Hu et al., 2017). There are numerous angiogenic molecules that take part in regulated new-vessel formation in DR, including VEGF (Tanaka et al., 1997). The microglia in retinas are activated in animal diabetic models (Rungger-Brandle et al., 2000;

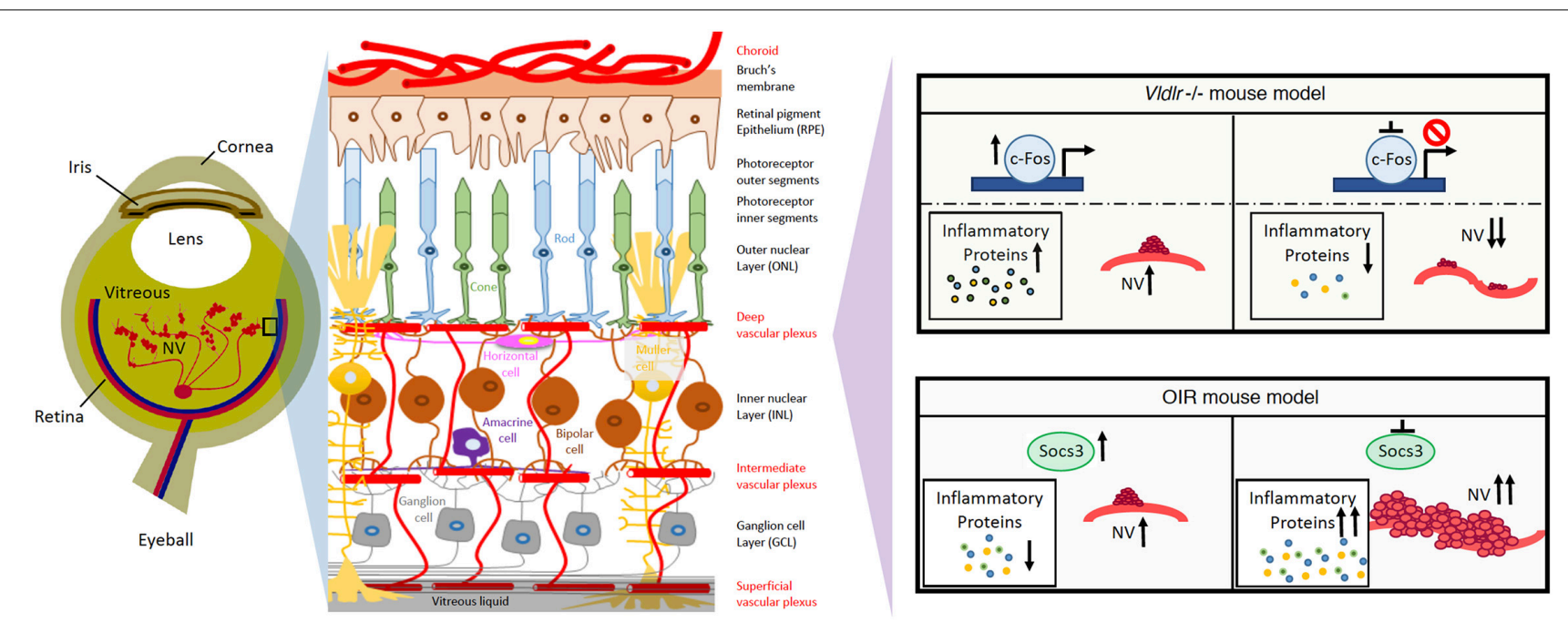

FIGURE 1 | Schematics of neuroinflammation and neovascularization in retina angiogenesis mouse models. Targeting master inflammatory regulators, Socs3 or c-Fos, may provide new ways to reduce neuroinflammation and prevent the development of NV in retinopathies. 
Kezic et al., 2013). Recent studies show that inflammatory changes in photoreceptors influence pathological angiogenesis in DR (Du et al., 2013; Kern and Berkowitz, 2015; Liu et al., 2016; Tonade et al., 2017). A dysregulation of communications among neurons including the photoreceptors, vascular cells, and glial cells plays a major role in the pathophysiology of proliferative DR (Antonetti et al., 2012), which is characterized by neovascularization, neuroinflammation and neurodegeneration.

\section{TARGETING NEUROINFLAMMATION IN NEOVASCULAR RETINAL DISEASES}

Although NV is the leading cause of blindness in eye diseases, including DR, AMD, and ROP, the detail mechanisms of the pathogenesis of NV are still not well understood (Zhang and $\mathrm{Ma}, 2007)$. Currently, ablation surgery, angiogenesis inhibitors and growth factor antibody therapy are the primary methods for NV treatment. Angiogenesis inhibitors include ranibizumab, bevacizumab and aflibercept. Bevacizumab is also known as Macugen, Avastin or Lucentis. All of the inhibitors have a similar function - they mainly inhibit the formation of new retinal blood vessels by inactivating VEGF (Avery et al., 2014; Fu et al., 2016). However, it is important to note that ablation surgery may cause damage to the retina, and anti-VEGF treatments may inhibit the growth of normal vessels and neurons (Fu et al., 2019). It is crucial to find new ways to treat retinal NV.

Because neuroinflammation is associated with retinal $\mathrm{NV}$ and promotes retinal $\mathrm{NV}$ ( $\mathrm{Fu}$ et al., 2018), it may be possible to target neuroinflammation to treat retinal NV (Rivera et al., 2017). Recently, there have been attempts to suppress NV through controlling key regulators of inflammatory signals in the eye. Suppressor of cytokine signaling 3 (SOCS3) is an inducible negative feedback regulator of growth factor and inflammation signaling (Stahl et al., 2012), and plays a critical role in regulating inflammatory responses. SOCS3 is able to prevent pathological angiogenesis, and a conditional loss of SOCS3 in endothelial cells results in increased pathological NV (Stahl et al., 2012). The expression of SOCS3 is significantly increased in neuronal and glial cells in the OIR mouse model (Sun et al., 2015). A conditional knockout of SOCS3 in neuronal and glial cells exacerbates glial cell activation and neuroinflammation while promoting VEGFA expression and retinal NV (Sun et al., 2015). In addition, knocking out tumor necrosis factor alpha ( $\mathrm{TNF} \alpha)$, one of the inflammatory cytokines, appears to be protective in the OIR mouse model (Gardiner et al., 2005). Therefore, targeting the master regulator of cytokine signaling, SOCS3, may provide a new way to reduce neuroinflammation and suppress $\mathrm{NV}$ in the eye (Figure 1).

\section{REFERENCES}

Akula, J. D., Hansen, R. M., Martinez-Perez, M. E., and Fulton, A. B. (2007a). Rod photoreceptor function predicts blood vessel abnormality in retinopathy of prematurity. Invest. Ophthalmol. Vis. Sci. 48, 4351-4359.

Akula, J. D., Mocko, J. A., Moskowitz, A., Hansen, R. M., and Fulton, A. B. (2007b). The oscillatory potentials of the dark-adapted electroretinogram
c-Fos is a proto-oncogene and is also important for many cellular functions. In human photoreceptor cells, c-Fos expression occurs throughout the development process (Yu et al., 1994). c-Fos regulates the expression of the rod-specific gene (He et al., 1998) and apoptosis in photoreceptor (Hafezi et al., 1997; Hobson et al., 2000; Poon et al., 2000). Additionally, c-Fos is strongly related to metabolic demands (Sun et al., 2017). In a retinal angiogenesis mouse model of very low-density lipid protein receptor (Vldlr) knockout mice, the expression levels of c-Fos and inflammatory cytokine ( $\mathrm{TNF} \alpha$ and Interleukin 6) are significantly increased in photoreceptors. Additionally, c-Fos controls retinal NV by modulating the neuroinflammation signals in this model (Sun et al., 2017). Therefore, targeting c-Fos may provide another way to reduce neuroinflammation in photoreceptors and prevent the development of $\mathrm{NV}$ in retinopathies (Figure $\mathbf{1}$ ).

In short, neuroinflammation is closely linked to angiogenesis, and improving the neuroinflammatory mechanism helps to inhibit retinal angiogenesis, while blocking inflammatory signals has also been reported to exacerbate retinal angiogenesis in the CNV model (Apte et al., 2006; Ambati et al., 2013). This happens because inflammation itself has two sides. In the early stages of neuroinflammation, activated glial cells work to clear damaged cells and protect the homeostasis of the retina. Persistent inflammation leads to a loss of control of glial cells, which in turn leads to an attack on their own cells through the secretion of inflammatory factors, exacerbating retinal angiogenesis. Therefore, inhibition of neuroinflammation to treat retinal angiogenesis is still controversial. To seek a better way to treat neuroinflammation, more investigation is needed to explore the detailed relationship between neuroinflammation and angiogenesis.

\section{AUTHOR CONTRIBUTIONS}

TW, DT, and YS contributed to the draft and edits of the manuscript. All authors approved the final manuscript.

\section{ACKNOWLEDGMENTS}

This work was supported by the NIH/NEI (R01EY030140 and R01EY029238), BrightFocus Foundation, Boston Children's Hospital Ophthalmology Foundation, and Boston Children's Hospital/IDDRC (1U54HD090255) (YS). We thank Wenbo Li and Xudong Wang for their discussion.

in retinopathy of prematurity. Invest. Ophthalmol. Vis. Sci. 48, 5788-5797.

Ambati, J., Atkinson, J. P., and Gelfand, B. D. (2013). Immunology of agerelated macular degeneration. Nat. Rev. Immunol. 13, 438-451. doi: 10.1038/nri 3459

Antonetti, D. A., Klein, R., and Gardner, T. W. (2012). Diabetic retinopathy. N. Engl. J. Med. 366, 1227-1239. 
Apte, R. S., Richter, J., Herndon, J., and Ferguson, T. A. (2006). Macrophages inhibit neovascularization in a murine model of age-related macular degeneration. PLoS Med. 3:e310. doi: 10.1371/journal.pmed.0030310

Avery, R. L., Castellarin, A. A., Steinle, N. C., Dhoot, D. S., Pieramici, D. J., See, R., et al. (2014). Systemic pharmacokinetics following intravitreal injections of ranibizumab, bevacizumab or aflibercept in patients with neovascular AMD. $\mathrm{Br}$. J. Ophthalmol. 98, 1636-1641. doi: 10.1136/bjophthalmol-2014-305252

Blencowe, H., Cousens, S., Oestergaard, M. Z., Chou, D., Moller, A. B., Narwal, R., et al. (2012). National, regional, and worldwide estimates of preterm birth rates in the year 2010 with time trends since 1990 for selected countries: a systematic analysis and implications. Lancet 379, 2162-2172. doi: 10.1016/S0140-6736(12) 60820-4

Caicedo, A., Espinosa-Heidmann, D. G., Pina, Y., Hernandez, E. P., and Cousins, S. W. (2005). Blood-derived macrophages infiltrate the retina and activate Muller glial cells under experimental choroidal neovascularization. Exp. Eye Res. 81, 38-47. doi: 10.1016/j.exer.2005.01.013

Campbell, M., and Humphries, P. (2012). The blood-retina barrier: tight junctions and barrier modulation. Adv. Exp. Med. Biol. 763, 70-84. doi: 10.1007/978-14614-4711-5_3

Campochiaro, P. A. (2013). Ocular neovascularization. J. Mol. Med. 91, 311-321.

Chang, R. C., Chiu, K., Ho, Y. S., and So, K. F. (2009). Modulation of neuroimmune responses on glia in the central nervous system: implication in therapeutic intervention against neuroinflammation. Cell. Mol. Immunol. 6, 317-326. doi: $10.1038 / \mathrm{cmi} .2009 .42$

Chen, M., Lechner, J., Zhao, J., Toth, L., Hogg, R., Silvestri, G., et al. (2016). STAT3 activation in circulating monocytes contributes to neovascular agerelated macular degeneration. Curr. Mol. Med. 16, 412-423. doi: 10.2174/ 1566524016666160324130031

Connor, K. M., Krah, N. M., Dennison, R. J., Aderman, C. M., Chen, J., Guerin, K. I., et al. (2009). Quantification of oxygen-induced retinopathy in the mouse: a model of vessel loss, vessel regrowth and pathological angiogenesis. Nat. Protoc. 4, 1565-1573. doi: 10.1038/nprot.2009.187

Connor, K. M., SanGiovanni, J. P., Lofqvist, C., Aderman, C. M., Chen, J., Higuchi, A., et al. (2007). Increased dietary intake of omega-3-polyunsaturated fatty acids reduces pathological retinal angiogenesis. Nat. Med. 13, 868-873. doi: $10.1038 / \mathrm{nm} 1591$

Cunha-Vaz, J., Bernardes, R., and Lobo, C. (2011). Blood-retinal barrier. Eur. J. Ophthalmol. 21(Suppl. 6), S3-S9. doi: 10.5301/EJO.2010.6049

Deliyanti, D., Talia, D. M., Zhu, T., Maxwell, M. J., Agrotis, A., Jerome, J. R., et al. (2017). Foxp3(+) Tregs are recruited to the retina to repair pathological angiogenesis. Nat. Commun. 8:748. doi: 10.1038/s41467-017-00751-w

Du, Y., Veenstra, A., Palczewski, K., and Kern, T. S. (2013). Photoreceptor cells are major contributors to diabetes-induced oxidative stress and local inflammation in the retina. Proc. Natl. Acad. Sci. U.S.A. 110, 16586-16591. doi: 10.1073/pnas. 1314575110

Espinosa-Heidmann, D. G., Suner, I. J., Hernandez, E. P., Monroy, D., Csaky, K. G., and Cousins, S. W. (2003). Macrophage depletion diminishes lesion size and severity in experimental choroidal neovascularization. Invest. Ophthalmol. Vis. Sci. 44, 3586-3592.

Fu, Z., Chen, C. T., Cagnone, G., Heckel, E., Sun, Y., Cakir, B., et al. (2019). Dyslipidemia in retinal metabolic disorders. EMBO Mol. Med. 11:e10473. doi: 10.15252/emmm.201910473

Fu, Z., Gong, Y., Lofqvist, C., Hellstrom, A., and Smith, L. E. (2016). Review: adiponectin in retinopathy. Biochim. Biophys. Acta 1862, 1392-1400. doi: 10. 1016/j.bbadis.2016.05.002

Fu, Z., Wang, Z., Liu, C. H., Gong, Y., Cakir, B., Liegl, R., et al. (2018). Fibroblast growth factor 21 protects photoreceptor function in type 1 diabetic mice. Diabetes 67, 974-985. doi: 10.2337/db17-0830

Gardiner, T. A., Gibson, D. S., de Gooyer, T. E., de la Cruz, V. F., McDonald, D. M., and Stitt, A. W. (2005). Inhibition of tumor necrosis factor-alpha improves physiological angiogenesis and reduces pathological neovascularization in ischemic retinopathy. Am. J. Pathol. 166, 637-644. doi: 10.1016/s0002-9440(10) 62284-5

Hafezi, F., Steinbach, J. P., Marti, A., Munz, K., Wang, Z. Q., Wagner, E. F., et al. (1997). The absence of c-fos prevents light-induced apoptotic cell death of photoreceptors in retinal degeneration in vivo. Nat. Med. 3, 346-349. doi: $10.1038 / \mathrm{nm} 0397-346$
He, L., Campbell, M. L., Srivastava, D., Blocker, Y. S., Harris, J. R., Swaroop, A., et al. (1998). Spatial and temporal expression of AP-1 responsive rod photoreceptor genes and bZIP transcription factors during development of the rat retina. Mol. Vis. 4:32.

Hobson, A. H., Donovan, M., Humphries, M. M., Tuohy, G., McNally, N., Carmody, R., et al. (2000). Apoptotic photoreceptor death in the rhodopsin knockout mouse in the presence and absence of c-fos. Exp. Eye Res. 71, 247-254. doi: 10.1006/exer.2000.0878

Hu, J., Dziumbla, S., Lin, J., Bibli, S. I., Zukunft, S., de Mos, J., et al. (2017). Inhibition of soluble epoxide hydrolase prevents diabetic retinopathy. Nature 552, 248-252. doi: 10.1038/nature25013

Kern, T. S., and Berkowitz, B. A. (2015). Photoreceptors in diabetic retinopathy. J. Diabetes Invest. 6, 371-380. doi: 10.1111/jdi.12312

Kezic, J. M., Chen, X., Rakoczy, E. P., and McMenamin, P. G. (2013). The effects of age and $\mathrm{Cx} 3 \mathrm{cr} 1$ deficiency on retinal microglia in the Ins2(Akita) diabetic mouse. Invest. Ophthalmol. Vis. Sci. 54, 854-863. doi: 10.1167/iovs.1210876

Klaassen, I., Van Noorden, C. J., and Schlingemann, R. O. (2013). Molecular basis of the inner blood-retinal barrier and its breakdown in diabetic macular edema and other pathological conditions. Progress Retin. Eye Res. 34, 19-48. doi: 10.1016/j.preteyeres.2013.02.001

Kumar, A., Zhao, L., Fariss, R. N., McMenamin, P. G., and Wong, W. T. (2014). Vascular associations and dynamic process motility in perivascular myeloid cells of the mouse choroid: implications for function and senescent change. Invest. Ophthalmol. Vis. Sci. 55, 1787-1796. doi: 10.1167/iovs.1313522

Leung, J. W., Lau, B. W., Chan, V. S., Lau, C. S., and So, K. F. (2016). Abnormal increase of neuronal precursor cells and exacerbated neuroinflammation in the corpus callosum in murine model of systemic lupus erythematosus. Rest. Neurol. Neurosci. 34, 443-453. doi: 10.3233/RNN160638

Liu, H., Tang, J., Du, Y., Saadane, A., Tonade, D., Samuels, I., et al. (2016). Photoreceptor cells influence retinal vascular degeneration in mouse models of retinal degeneration and diabetes. Invest. Ophthalmol. Vis. Sci. 57, 4272-4281. doi: 10.1167/iovs.16-19415

Lutty, G. A., Chan-Ling, T., Phelps, D. L., Adamis, A. P., Berns, K. I., Chan, C. K., et al. (2006). Proceedings of the third international symposium on retinopathy of prematurity: an update on rop from the lab to the nursery (November 2003, Anaheim, California). Mol. Vis. 12, 532-580.

Noel, A., Jost, M., Lambert, V., Lecomte, J., and Rakic, J. M. (2007). Antiangiogenic therapy of exudative age-related macular degeneration: current progress and emerging concepts. Trends molecular Med. 13, 345-352. doi: 10.1016/j.molmed.2007.06.005

Poon, H. K., Tso, M. O., and Lam, T. T. (2000). c-Fos protein in photoreceptor cell death after photic injury in rats. Invest. Ophthalmol. Vis. Sci. 41, 2755-2758.

Rivera, J. C., Holm, M., Austeng, D., Morken, T. S., Zhou, T., BeaudryRichard, A., et al. (2017). Retinopathy of prematurity: inflammation, choroidal degeneration, and novel promising therapeutic strategies. J. Neuroinflamm. 14:165. doi: 10.1186/s12974-017-0943-1

Rungger-Brandle, E., Dosso, A. A., and Leuenberger, P. M. (2000). Glial reactivity, an early feature of diabetic retinopathy. Invest. Ophthalmol. Vis. Sci. 41, 19711980.

Smith, L. E., Wesolowski, E., McLellan, A., Kostyk, S. K., D’Amato, R., Sullivan, R., et al. (1994). Oxygen-induced retinopathy in the mouse. Invest. Ophthalmol. Vis. Sci. 35, 101-111.

Spaide, R. F. (2006). Rationale for combination therapies for choroidal neovascularization. Am. J. Ophthalmol. 141, 149-156. doi: 10.1016/j.ajo.2005. 07.025

Stahl, A., Joyal, J. S., Chen, J., Sapieha, P., Juan, A. M., Hatton, C. J., et al. (2012). SOCS3 is an endogenous inhibitor of pathologic angiogenesis. Blood 120, 2925-2929. doi: 10.1182/blood-2012-04-422527

Sun, Y., Ju, M., Lin, Z., Fredrick, T. W., Evans, L. P., Tian, K. T., et al. (2015). SOCS3 in retinal neurons and glial cells suppresses VEGF signaling to prevent pathological neovascular growth. Sci. Signal. 8:ra94. doi: 10.1126/scisignal. aaa8695

Sun, Y., Lin, Z., Liu, C. H., Gong, Y., Liegl, R., Fredrick, T. W., et al. (2017). Inflammatory signals from photoreceptor modulate pathological retinal 
angiogenesis via c-Fos. J. Exp. Med. 214, 1753-1767. doi: 10.1084/jem.2016 1645

Tanaka, Y., Katoh, S., Hori, S., Miura, M., and Yamashita, H. (1997). Vascular endothelial growth factor in diabetic retinopathy. Lancet 349:1520. doi: 10 . 1016/s0140-6736(05)62099-5

Tasman, W., Patz, A., McNamara, J. A., Kaiser, R. S., Trese, M. T., and Smith, B. T. (2006). Retinopathy of prematurity: the life of a lifetime disease. Am. J. Ophthalmol. 141, 167-174.

Tonade, D., Liu, H., and Kern, T. S. (2016). Photoreceptor cells produce inflammatory mediators that contribute to endothelial cell death in diabetes. Invest. Ophthalmol. Vis. Sci. 57, 4264-4271.

Tonade, D., Liu, H., Palczewski, K., and Kern, T. S. (2017). Photoreceptor cells produce inflammatory products that contribute to retinal vascular permeability in a mouse model of diabetes. Diabetologia 60, 2111-2120. doi: 10.1007/s00125017-4381-5

Xing, X., Liu, F., Xiao, J., and So, K. F. (2016). Neuro-protective mechanisms of Lycium barbarum. Neuromol. Med. 18, 253-263. doi: 10.1007/s12017-0168393-y

Yu, M. C., Li, W. W., Liu, K., and Yew, D. T. (1994). An immunohistochemical study of the c-fos protooncogene in the developing human retina. Neuroscience 60, 983-987. doi: 10.1016/0306-4522(94)90 $277-1$

Zhang, S. X., and Ma, J. X. (2007). Ocular neovascularization: implication of endogenous angiogenic inhibitors and potential therapy. Prog. Retin. Eye Res. 26, 1-37. doi: 10.1016/j.preteyeres.2006. 09.002

Zhou, J., Pham, L., Zhang, N., He, S., Gamulescu, M. A., Spee, C., et al. (2005). Neutrophils promote experimental choroidal neovascularization. Mol. Vis. 11, 414-424.

Conflict of Interest: The authors declare that the research was conducted in the absence of any commercial or financial relationships that could be construed as a potential conflict of interest.

Copyright (c) 2020 Wang, Tsirukis and Sun. This is an open-access article distributed under the terms of the Creative Commons Attribution License (CC BY). The use, distribution or reproduction in other forums is permitted, provided the original author(s) and the copyright owner(s) are credited and that the original publication in this journal is cited, in accordance with accepted academic practice. No use, distribution or reproduction is permitted which does not comply with these terms. 